\title{
Evaluation of variation in dimensions of sella turcica in patients with unilateral cleft lip and palate as compared to Class I controls
}

\author{
Himija Karia $^{1 *}$, Sunita Shrivastav ${ }^{2}$ and Ashokkumar Karia ${ }^{3}$ \\ ${ }^{1}$ Orthodontics and Dentofacial Orthopedics, Vspm Dental College and Research Centre, Nagpur, India \\ ${ }^{2}$ Orthodontics and Dentofacial Orthopedics, Sharad Pawar Dental College, Sawangi, Wardha, India \\ ${ }^{3}$ Orthodontics and Dentofacial Orthopedics, Practicing Orthodontist, Getwell Hospital, Nagpur, India
}

\begin{abstract}
Background: Sella turcica forms the junction of the anterior and posterior cranial base and is also a key point for the migration of neural crest cells to the fronto-nasal and maxillary development fields. An abnormal sella turcica might induce abnormal fronto-nasal and maxillary morphology. Patients with Cleft Lip and/ or Palate (CLP) not only have abnormality in naso-maxillary region but a restricted development of other craniofacial structures is often seen.
\end{abstract}

Aim: This retrospective study was designed to evaluate variation in the length, width, depth and angulation of the sella turcica in patients with CLP and to compare them with subjects without CLP.

Method: Pre-treatment lateral cephalograms of 25 UCLP subjects was traced and the dimensions of the sella turcica were compared with those of 25 Angle Class I subjects.

Result: Statistical analysis revealed a significantly smaller length, width and depth of the sella turcica in subjects with cleft as compared to controls. The angulation of the sella turcica was increased in the patients with cleft as compared to the control group.

Conclusion: There is variation in the dimensions of sella turcica in subjects with cleft. This might be the reason for the altered growth seen in the cleft subjects. This pilot study paves way for extensive research in the field of cranio-facial growth and its implications on the NMC and airways of patients with CLP.

\section{Introduction}

The cleft of the lip and palate is the most common congenital anomaly affecting the cranio-facial region [1,2]. The etiology of CLP is said to be multi-factorial having both genetic and environmental causes. Clefts may be localized defects or may be associated with widespread structural changes in other parts of the skull [3]. Several studies have shown that the growth and displacement of the maxilla is directly linked to the growth and angulation of the cranial base [4-6]. Hence it may be assumed that any anomaly in the cranial base may have impact on the growth as well as spatial position of the naso-maxillary complex.

Sella turcica is a significant anatomical landmark in the base of the skull. It is not only remarkable as it is a prominent cephalometric landmark of the cranial base but it also houses the pituitary gland. Abnormalities in pituitary gland may manifest as aberrations in the size and shape of the sella turcica [7-9]. An anatomically normal sella turcica lies on the body of sphenoid bone; bounded anteriorly by tuberculum sellae and posteriorly by dorsum sellae. Two anterior and two posterior clinoid processes project over the pituitary fossa. The anterior clinoid processes are formed by the medial and anterior prolongations of the lesser wing of the sphenoid bone, and the posterior clinoid processes represent terminations of the dorsum sellae [10].

During embryological development, sella turcica region is the key point for the migration of the neural crest cells to the fronto nasal and maxillary developmental fields [11]. The development of the anterior part of the pituitary gland, sella turcica and teeth share the involvement of neural crest cells. Also the dental epithelial progenitor cells differentiate through sequential and reciprocal interaction with neural crest derived mesenchyme [12]. Hence it may be assumed that abnormalities in the size and shape of sella turcica may be directly or indirectly linked to the congenital deformities of the naso-maxillary complex such as CLP.

Numerous studies have reported aberration in the dimensions of sella turcica in relation to genetic disorders [13-15]. Studies have also shown variation in the morphology of the sella turcica in skeletal Class I, Class II and Class III malocclusion, with the dimension of the sella turcica being smaller in Class II and largest in Class III [16,17]. Bridging of sella turcica has also been found in Class III cases [18].

Axelsson, et al. [19] conducted a study on subjects with Williams syndrome and reported that the mean dimensions of the sella turcica in these individuals are smaller than those of control group.

${ }^{\star}$ Correspondence to: Himija Karia, A-3, Indrasagar Apts, R.N.Tagore Road, Civil Lines, Nagpur 440001, India, Tel: +91 7709454893; E-mail: himijakaria@ gmail.com

Key words: sella turcica, cleft lip, palate

Received: July 09, 2019; Accepted: August 01, 2019; Published: August 05, 2019 
Nielson, et al. [20] found morphological deviations and malformations in the walls of the sella turcica in subjects with cleft lip and palate. Alkofied [21] conducted a cephalometric study and reported that $63.2 \%$ subjects with CLP had an abnormal shape of the sella turcica.

Therefore it may be assumed that there might be a positive correlation between the morphology of the sella turcica and CLP. Although CLP is one of the most common congenital anomaly its etiology is not completely understood. Cleft may be a localized defect, or it may have implications on other developmentally related parts of the skull. Sella turcica being an important area developmentally and structurally, it can provide some insights into the process of clefting and help in diagnosing as well as predicting the nature of clefts.

Not many studies have been conducted to investigate the variation in dimensions of the sella turcica in patients with cleft lip and/ or palate. Hence the purpose of this study was to measure the length, width, depth and angulation of the sella turcica in patients with CLP and to compare them with subjects without CLP.

\section{Materials and method}

A retrospective study was carried out at ${ }^{* * * * * * * * * * * *}$. The ethical clearance was obtained in the month of October 2013 and the study was completed by July 2014. The archives of the department of Orthodontics were searched for the pre treatment lateral cephalograms of 25 patients with unilateral cleft lip and palate (12 Males, 13 Females). This comprised the study group. For the control group, 25 pre treatment lateral cephalograms (13Males, 12 Females) of patients with Angle Class I malocclusion who met the following inclusion criteria were selected from the archives.

\section{Inclusion / exclusion criteria:}

All individuals were between 15- 25 years of age. No patient with any major illness, underlying medical problems or syndromes was included. Patients in the control group were selected based on ANB angle, (ANB $0-4^{\circ}$ ) and Witts appraisal (0 for males and -1 for females).

\section{Method}

All the selected radiographs were digital and were taken by a trained radiographer in a standardized manner using the same cephalostat. (planmeca proline $\mathrm{cm}$ ). Exposure parameters were set at $80 \mathrm{kvp}, 10 \mathrm{~mA}$ and 0.8 -seconds. $8 \times 10$ inch Kodak green film was used with the patient's head in postural position. The digital radiographs were of good quality and clearly showed the sella turcica anatomy. All the lateral cephalograms were traced on cellulose acetate sheets and measurements were made in the following manner.

\section{Measurements}

\section{Length of sella at opening: (DS-TS) [Figure 1]}

The interclinoidal distance i.e. the shortest distance between the clinoidal processes was measured.

\section{Width of the sella: (Cp-Ca) [Figure 1]}

The horizontal distance between the most concave points on the inner margin of sella turcica was measured.

\section{Depth of the sella: [Figure 1]}

Distance from the centre of the interclinoidal line to the deepest point on the floor of the pituitary fossa (D) was measured.

\section{Angulation of sella turcica: [Figure 2]}

The line forming the anterior and the posterior clinoidal process was extended and the outer inferior angle was measured as shown in the figure.

\section{Method error}

All the tracings were done by a single observer $(\mathrm{HK})$ and were rechecked by another observer (SS). The readings were measured again at an interval of three weeks by the same investigator (HK) and the method error was calculated using Dahlberg's coefficient for assessment of intra-examiner error. The intra-examiner reliability was found to be in the range of $0.75-0.86$. The resulting measurements showed good reproducibility of the retraced radiographs.

\section{Statistical analysis}

The data was analyzed using SPSS version 16.0 software. Descriptive statistics was carried out to calculate mean \& standard deviation. Unpaired $\mathrm{T}$ test was applied to draw comparison between readings obtained from the cleft group and the control group. Chi square test was used to check any correlation of the dimensions of the sella with age or sex. The confidence interval was set at $95 \%$, p value $<0.05$ was considered significant.

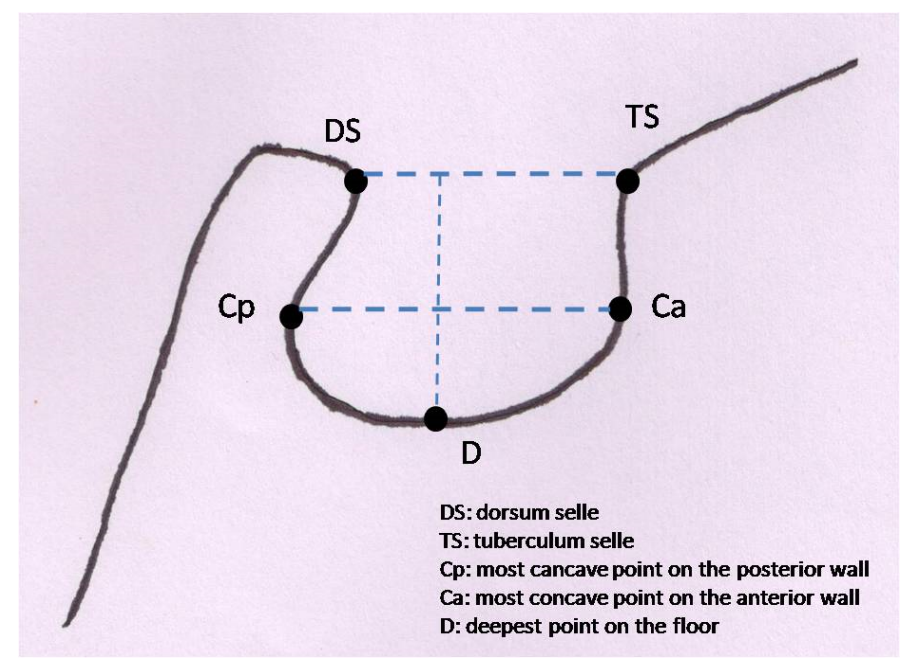

Figure 1. Measurement of length, width and depth of sella

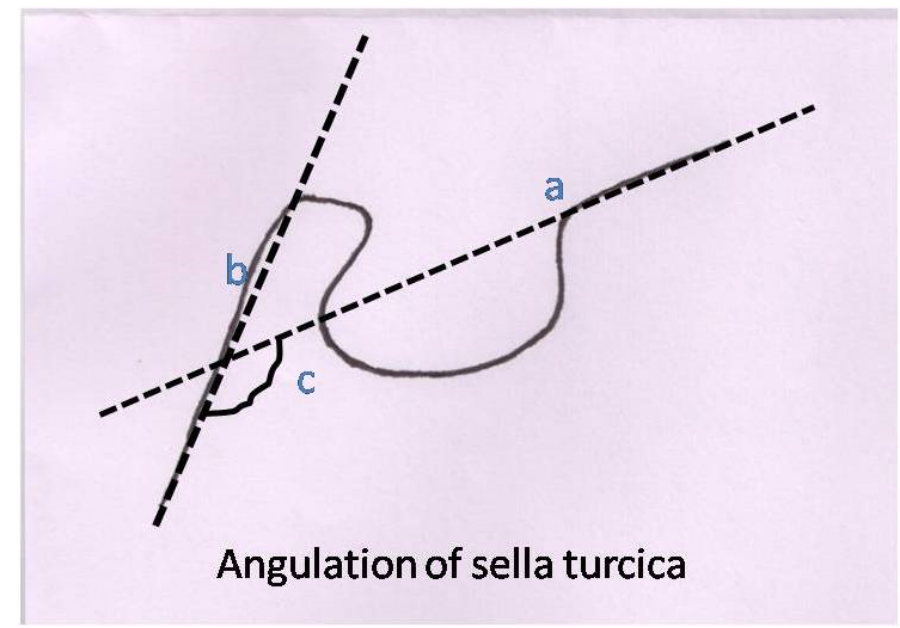

Figure 2. a: extension of anterior clinoidal process; b: extension of posterior clinoidal process; c: outer inferior angle between ' $a$ ' $\&$ 'b' 


\section{Result}

The statistical analysis revealed that the length, width and depth of the sella turcica were found to be significantly reduced $(\mathbf{p}<\mathbf{0 . 0 5})$ in the Cleft group as compared to the control group. However, the angulation of the sella turcica was found to be significantly increased in the cleft subject as compared to the subjects from the control group. $(\mathbf{p}=\mathbf{0 . 0 4 8})$.

The mean length of the sella turcica in cleft group is $3.36 \mathrm{~mm}$ whereas in normal individuals was found to be $5.88 \mathrm{~mm}$. The average width of the sella in cleft group was found to be $7.24 \mathrm{~mm}$ while for normal individuals it was $8.28 \mathrm{~mm}$. The average value for the depth of sella in cleft and normal groups was $6.64 \mathrm{~mm}$ and $8.00 \mathrm{~mm}$ respectively. The mean angulation of sella in cleft and normal group was 133.88 degrees and 127.16 degrees respectively.

When comparison was drawn between males and females in the control as well as cleft group; all linear measurements showed slightly higher value for male subjects in both the groups. However, no significant difference was found in the dimensions of the sella turcica between males and females. Only the angulation of the sella was slightly increased in the females of the cleft group as compared to the males of cleft group. $(\mathrm{p}=\mathbf{0 . 0 4 3})$.

\section{Discussion}

The sella turcica is a crucial landmark in the base of the skull. It not only provides a stable reference point for the cephalometric analysis, it also houses the pituitary gland. As the sella turcica lies at the junction of the anterior and posterior cranial base, it is considered that the cranial base flexes at the sella turcica, allowing man to assume an erect posture [5]. Sella turcica is also a strategic region for the migration of neural crest cells to the fronto-nasal and maxillary development fields [22]. Due to its strategic importance as an anatomical landmark, any malformation or aberration in the size and shape of the sella turcica may have widespread impact on the growth of the entire cranio-facial region.

Some previous studies [13-15] have shown presence of abnormal morphology of the sella turcica in syndromic cases. Aberrations in the shape and size of the sella turcica have been reported in spina bifida, Down syndrome, trisomy 18 , holoprosencephaly etc. As cleft of the lip and / or palate is one of the most common anomalies of the craniofacial complex; it may be assumed that the anatomy of the sella turcica may show variation in CLP cases also.

Alkofied in 2008 found abnormal morphology of the pituitary fossa in CLP cases through his cephalometric study [21]. Kjaer found altered shape of the sella in a UCLP fetus [23]. Neilson reported deviated morphology of the sella in more than $50 \%$ of the cleft subjects examined by him [20].

Most of the previous studies have examined the shape of the sella turcica in cleft subjects [20]. However, shape is a subjective parameter. Not many studies have objectively measured the difference in the size of sella turcica among cleft and non-cleft subjects. Hence this cephalometric pilot study was planned to evaluate the variations in the dimensions of the sella turcica among subjects with and without CLP.

The sample consisted of good quality pre-treatment lateral cephalometric radiographs of 25 patients with UCLP and 25 Angle Class I individuals searched from the archives of the department of Orthodontics, ${ }^{* * * * * * * * * * * *}$. All the subjects were above 15 years of age and none of them had any other underlying ailment.
Lateral cephalograms were used in this pilot study as lateral cephalograms are routinely taken for all patients seeking Orthodontic treatment. Lateral cephalogram allows easy measurement of the dimensions of the sella turcica without any need for additional radiation to the patient.

Only UCLP patients were chosen for this study as these patients are reported to show maximum variation of the sella turcica morphology among subjects with different types of cleft. Nielsen studied 40 CLP subjects and reported that the most severe deviations in the sellar morphology was found in UCLP cases [20]. Alkofide also reported that the most common dysmorphological trait of the sella turcica i.e irregularity or notching of the posterior part of the dorsum sellae, was found more frequently in UCLP subjects [21].

All subjects in the present study were between 15 years -25 years of age to eliminate any confounding bias due to age. Alkofide reported that sella dimensions increase with age upto 14 years [21]. Preston also stated that a close correlation between the area of the sella and age can be found [24]. Bjork [25] and Melsen [26] stated that the morphology of sella turcica does not change significantly after 12 years of age.

In the present study, statistical analysis revealed that the length, width and depth of the sella turcica was significantly reduced $(\mathrm{p}<0.05)$ (Table 1) in subjects with cleft as compared to the control group. All the linear measurements appeared to be smaller in the cleft group than in normal subjects. This is in agreement with the findings of Alkofide who reported a smaller size of the sella turcica in patients with cleft [21]. Axelsson, et al. also reported similar findings when comparing subjects with Williams syndrome and normal individuals [19]. He stated that both female and male subjects with Williams syndrome had smaller sella turcica sizes than the control group.

Although the mean values for width and depth are found to be smaller in this study than those reported by Alkofide, the difference may be attributed to the different population studied [21].

When comparisons were made between males and females in both the groups, results show that the dimensions of the sella turcica are slightly larger in males as compared to females though not statistically significant.

Another parameter evaluated in this study is the angulation of the sella turcica. Sella forms the junction of the anterior and the posterior cranial base. In man, the cranial base flexes at this junction as an evolutionary change to allow man to adopt an erect posture [5]. Although this parameter has not been widely studied before, it is comparable to the cranial base angle formed between the nasion - sella $(\mathrm{N}-\mathrm{S})$ and sella - basion (S-Ba) lines, due to its anatomical association with the anterior (N-S) and posterior cranial base ( $\mathrm{S}-\mathrm{Ba})$.

The results show that the angulation of sella is significantly increased ( $\mathbf{p}=\mathbf{0 . 0 4 8}$ ) (table 1 ) in the cleft patients as compared to the normal group. This may be attributed to the bridging and increased flexure of the cranial base in the cleft sample. Bridging has been reported previously by several authors such as Camp [27] and Becktor [28].

The angulation of the sella also shows significant sexual dimorphism in this study. The angulation of sella is found to be significantly greater ( $p$ $=\mathbf{0 . 0 4 3}$ ) in females as compared to males in the cleft group. (Tables 2 and 3 )

A greater cranial base angle in cleft patients may not only contribute to a more posterior positioning of the posterior cranial base it also brings the facial structures closer to the vertebral column which diminishes the antero-posterior depth of the upper airway resulting in greater incidence of airway insufficiency in cleft patients [29]. 
Table 1. Comparison of length, width, depth and angulation of sella turcica between control group and subjects with CLP

\begin{tabular}{|c|c|c|c|c|c|c|c|}
\hline \multicolumn{6}{|c|}{ Group Statistics of Control group subjects Vs subjects with CLP } & \multirow{2}{*}{ T test } & \multirow{2}{*}{ P value } \\
\hline & Group & Sample size & Mean & Std. Deviation & Std. Error Mean & & \\
\hline \multirow{2}{*}{ LENGTH OF SELLA } & Control & 25 & 5.88 & 1.394 & 0.279 & \multirow{2}{*}{6.8} & \multirow{2}{*}{$<0.001$} \\
\hline & CLP & 25 & 3.36 & 1.221 & 0.244 & & \\
\hline \multirow{2}{*}{ WIDTH OF SELLA } & Control & 25 & 8.28 & 0.737 & 0.147 & \multirow{2}{*}{4.05} & \multirow{2}{*}{$<0.001$} \\
\hline & CLP & 25 & 7.24 & 1.052 & 0.210 & & \\
\hline \multirow{2}{*}{ DEPTH OF SELLA } & Control & 25 & 8.00 & 0.764 & 0.153 & \multirow{2}{*}{4.24} & \multirow{2}{*}{$<0.001$} \\
\hline & CLP & 25 & 6.64 & 1.411 & 0.282 & & \\
\hline \multirow{2}{*}{ ANGULATION OF SELLA } & Control & 25 & 127.16 & 11.739 & 2.348 & \multirow{2}{*}{2.02} & \multirow{2}{*}{0.048} \\
\hline & CLP & 25 & 133.88 & 11.717 & 2.343 & & \\
\hline
\end{tabular}

Table 2. Comparison of length, width, depth and angulation of sella turcica among males and females of the control group

\begin{tabular}{|c|c|c|c|c|c|c|c|}
\hline \multicolumn{6}{|c|}{ Group Statistics of Male Vs Female in the control group } & \multirow{2}{*}{ T test } & \multirow{2}{*}{ P value } \\
\hline & & No. & Mean & Std. Deviation & Std. Error Mean & & \\
\hline \multirow{2}{*}{ LENGTH OFSELLA } & Male & 13 & 6.00 & 1.354 & 0.376 & \multirow{2}{*}{0.44} & \multirow{2}{*}{0.66} \\
\hline & Female & 12 & 5.75 & 1.485 & 0.429 & & \\
\hline \multirow{2}{*}{ WIDTH OF SELLA } & Male & 13 & 8.31 & 0.751 & 0.208 & \multirow{2}{*}{0.192} & \multirow{2}{*}{0.85} \\
\hline & Female & 12 & 8.25 & 0.754 & 0.218 & & \\
\hline \multirow{2}{*}{ DEPTH OF SELLA } & Male & 13 & 8.08 & 0.760 & 0.211 & \multirow{2}{*}{0.516} & \multirow{2}{*}{0.611} \\
\hline & Female & 12 & 7.92 & 0.793 & 0.229 & & \\
\hline \multirow{2}{*}{ ANGULATION OF SELLA } & Male & 13 & 126.62 & 13.494 & 3.743 & \multirow{2}{*}{0.237} & \multirow{2}{*}{0.815} \\
\hline & Female & 12 & 127.75 & 10.065 & 2.905 & & \\
\hline
\end{tabular}

Table 3. Comparison of length, width, depth and angulation of sella turcica among males and females of the cleft group

\begin{tabular}{|c|c|c|c|c|c|c|c|}
\hline \multicolumn{6}{|c|}{ Group Statistics of Male vs female in cleft group } & \multirow{2}{*}{ T test } & \multirow{2}{*}{ P value } \\
\hline & & No. & Mean & Std. Deviation & Std. Error Mean & & \\
\hline \multirow{2}{*}{ LENGTH OF SELLA } & Male & 12 & 3.67 & 1.435 & 0.414 & \multirow{2}{*}{1.22} & \multirow{2}{*}{0.235} \\
\hline & Female & 13 & 3.08 & 0.954 & 0.265 & & \\
\hline \multirow{2}{*}{ WIDTH OF SELLA } & Male & 12 & 7.33 & 1.155 & 0.333 & \multirow{2}{*}{0.419} & \multirow{2}{*}{0.679} \\
\hline & Female & 13 & 7.15 & 0.987 & 0.274 & & \\
\hline \multirow{2}{*}{ DEPTH OF SELLA } & Male & 12 & 6.92 & 1.505 & 0.434 & \multirow{2}{*}{0.940} & \multirow{2}{*}{0.357} \\
\hline & Female & 13 & 6.38 & 1.325 & 0.368 & & \\
\hline \multirow{2}{*}{ ANGULATION OF SELLA } & Male & 12 & 129.00 & 11.909 & 3.438 & \multirow{2}{*}{-2.14} & \multirow{2}{*}{0.043} \\
\hline & Female & 13 & 138.38 & 9.938 & 2.756 & & \\
\hline
\end{tabular}

Our results match with the findings of Moss [30] who reported a difference of $14^{\circ}$ between the cleft and normal subjects. Harris [29] reported that the cranial base flexed more in the CLP patients than the normal. Increased flexion was also reported by Ross [3] and Dahl [31].

In contrast Brader [32], McNiel [33] and Bishara et al. [34] did not find any significant difference in the cranial base angle between the cleft and the control group. Sandham and Cheng, et al. [35] reported a significant difference only in females. Krogman, et al. [36] found a larger cranial base angle in females, in the more severe cleft-type. The larger sellar angle in cleft cases suggests that clefting and cranial flexion, which occur almost simultaneously in embryogenesis, may be interlinked processes.

The formation of sella turcica and the pituitary gland are complex processes. The anterior part is thought to form from neural crest cells while, the posterior part develops from the para-axial mesoderm [37]. Both structures develop at approximately 7 weeks of gestation, and if any disturbance occurs in this area it remains throughout life. The time of formation of the sella and the cells involved are closely associated with the development of maxilla, hence it may be assumed that any aberration leading to cleft may be associated with some fault at the level of the sella turcica.

Some investigators have also shown that a relationship exists between cleft of the lip and palate and pituitary function [38-40]. Previous reports [41] have identified that in children with clefts, especially those involving the palate, a shorter stature is present as compared to their unaffected peers.

These findings indicate that the development of the sella turcica, pituitary gland and the naso-maxillary complex may be interlinked.

Further studies in this direction may be able to establish a relationship between clefting and development of the cranial base structures such as sella turcica.

\section{Limitations of this study and future scope}

This pilot study was carried out on a small sample size, however future studies may be carried out using a larger sample and better imaging modalities such as CBCT which can give a three dimensional evaluation of the variation in size of the sella turcica in cleft subjects. Lateral cephalograms were used in this study as these are the basic diagnostic records obtained for all orthodontic cases, yet it has limitations due to its $2 \mathrm{D}$ nature.

\section{Conclusion}

The result of this pilot study indicates that there is indeed statistically significant variation in the dimensions of the sella turcica in individuals with and without cleft. This study also paves way for further endocrinological research to determine if there is any abnormality in the pituitary function in subjects with smaller sella cavity and CLP. 
The findings of these studies will not only help in better understanding of the development of the cranio-facial structures at the genetic level, it can also widen the scope of management of CLP patients.

\section{Funding}

\section{None}

\section{Conflict of interest}

None

\section{References}

1. Vanderas AP (1987) Incidence of cleft lip, cleft palate, and cleft lip and palate among races: a review. Cleft Palate J 24: 216-225. [Crossref]

2. Sayetta RB, Weinrich MC, Coston GN (1989) Incidence and prevalence of cleft lip and palate: what we think we know. Cleft Palate J 26: 242-247. [Crossref]

3. Ross RB (1965) Cranial base in children with lip and palate clefts. Cleft Palate J 31: 157-166. [Crossref]

4. Enlow DH, Hans MG (1996) Essentials of Facial Growth. Philadelphia: WB Saunders.

5. Shridhar Premkumar. Textbook of Craniofacial Growth. Jaypee Brothers Medical Publishers (P) LTD.

6. Hopkin GB, Houston WJ, James GA (1968) The cranial base as an aetiological factor in malocclusion. Angle Orthod 38: 250-255. [Crossref]

7. Amar AP, Weiss MH (2003) Pituitary anatomy and physiology. Neurosurg Clin N Am 14: 11-23. [Crossref]

8. Andredaki M, Koumantanou A, Dorotheou D, Halazonetis DJ (2007) A cephalometric morphometric study of the sella turcica. Eur J Orthod 29: 449-56.

9. Pisaneschi M, Kapoor G (2005) Imaging of the sella and parasellar region. Neuroimaging Clin N Am 15: 203-219. [Crossref]

10. Sathyanarayana HP, Kailasam V, Chitharanjan AB (2013) Sella turcica-Its importance in orthodontics and craniofacial morphology. Dent Res $J$ (Isfahan) 10: 571-575. [Crossref]

11. Miletich I, Sharpe PT (2004) Neural crest contribution to mammalian tooth formation. Birth Defects Res C Embryo Today 72: 200-212. [Crossref]

12. Morotomi T, Kawano S, Toyono T, Kitamura C, Terashita M, et al. (2005) In vitro differentiation of dental epithelial progenitor cells through epithelial-mesenchymal interactions. Arch Oral Biol 50: 695-705. [Crossref]

13. Kjaer I, Wagner A, Madsen P, Blichfeldt S, Ramussen K, et al. (1998) The sella turcica in children with lumbosacral myelomeningocele. Eur J Orthod 20: 443-448. [Crossref]

14. Kjaer I, Keeling JW, Reintoft I, Hjalgrim H, Nolting D, et al. (1998) Pituitary gland and sella turcica in human trisomy 18 fetuses. Am J Med Genet 76: 87-92. [Crossref]

15. Kjaer I, Keeling JW, Reintoft I, Nolting D, Fischer-Hansen B (1998) Pituitary gland and sella turcica in human trisomy 21 fetuses related to axial skeletal development. $\mathrm{Am}$ J Med Genet 80: 494-500. [Crossref]

16. Alkofide EA (2007) The shape and size of the sella turcica in skeletal Class I, Class II, and Class III Saudi subjects. Eur J Orthod 29: 457-463. [Crossref]

17. Marsan G, Oztas E (2009) Incidence of bridging and dimensions of sella turcica in class I and class III Turkish adult female patients. World J Orthod 10: 99-103. [Crossref]

18. Meyer-Marcotty P, Reuther T, Stellzig-Eisenhauer A (2010) Bridging of the sella turcica in skeletal Class III subjects. Eur J Orthod 32: 148-153. [Crossref]
19. Axelsson S, Storhaug K, Kjaer I (2004b) Post-natal size and morphology of the sella turcica in Williams syndrome. Eur J Orthod 26: 613-621. [Crossref]

20. Nielsen BW, Mølsted K, Kjaer I (2005) Maxillary and sella turcica morphology in newborns with cleft lip and palate. Cleft Palate Craniofac J 42: 610-617. [Crossref]

21. Alkofide EA (2008) Sella Turcica Morphology and Dimensions in Cleft Subjects. Cleft Palate Craniofac J 45: 647-53. [Crossref]

22. Kjaer I, Keeling JW, Fischer-Hansen B (1999) The Prenatal Human Cranium—Normal and Pathologic Development. Copenhagen: Munksgaard.

23. Kjaer I, Fischer-Hansen B (2000) The prenatal pituitary gland-hidden and forgotten Pediatr Neurol 22: 155-156. [Crossref]

24. Preston CB (1979) Pituitary fossa size and facial type. Am J Orthod 75: 259-263. [Crossref]

25. Bjo"rk A (1955) Cranial base development. Am J Orthod 41: 198-225. [Crossref]

26. Melsen B (1974) The cranial base. The postnatal development of the cranial base studied historically on human autopsy material. Acta Odontol Scand 32: 57-71.

27. Camp JD (1924) Normal and pathological anatomy of the sella turcica as revealed by roentgenograms. Am J Roentgenol 12: 143-156.

28. Becktor JP, Einersen S, Kjaer I (2000) A sella turcica bridge in subjects with severe craniofacial deviations. Eur J Orthod 22: 69-74. [Crossref]

29. Harris EF (1993) Size and form of the cranial base in isolated cleft lip and palate. Cleft Palate Craniofac $J$ 30: 170-174. [Crossref]

30. MOSS ML (1956) Malformations of the skull base associated with cleft palate deformity. Plast Reconstr Surg (1946) 17: 226-234. [Crossref]

31. Dahl E (1970) Craniofacial morphology in congenital clefts of the lip and palate. An x-ray cephalometric study of young adult males. Acta Odontol Scand 28: Suppl 57 11+. [Crossref]

32. Brader ACA (1957) cephalometric x-ray appraisal of morphological variations in cranial base and associated pharyngeal structures: implications in cleft palate therapy. Angle Orthod 27: 179-195.

33. McNeill RW (1962) a roentgen cephalometric study of naso-pharyngeal and cranial base growth in cleft palate children. Intrnat Assoc dent Res p. 41.

34. Bishara SE, Iversen WW (1974) Cephalometric comparisons on the cranial base and face in individuals with isolated clefts of the palate. Cleft Palate $J$ 11: 162-175. [Crossref]

35. Sandham A, Cheng L (1988) Cranial base and cleft lip and palate. Angle Orthod 58 163-168. [Crossref]

36. Krogman WM, Jain RB, Long RE Jr (1982) Sex differences in craniofacial growth from one month to ten years of cleft lip and palate. Cleft Palate J 19: 62-71. [Crossref]

37. Kjaer I, Fischer-Hansen B (1995) The adenohypophysis and the cranial base in early human development. J Craniofac Genet Dev Biol 15: 157-161. [Crossref]

38. Laron Z, Taube E, Kaplan I (1969) Pituitary growth hormone insufficiency associated with cleft lip and palate. An embryonal developmental defect. Helv Paediatr Acta 24 576-581. [Crossref]

39. Sultan Z, Gnanaratnam J, Sharief N (1996) Isolated aplasia of the anterior pituitary gland with unusual associations. Clin Dysmorphol 5: 347-350. [Crossref]

40. Zuppinger KA, Sutter M, Zurbrugg RP, Joss EE, Oetliker O (1971) Cleft lip and choriodeal coloboma associated with multiple hypothalamo-pituitary dysfunctions. $J$ Clin Endocrinol Metab 22: 934-939. [Crossref]

41. Bowers EJ, Mayro RF, Whitaker LA, Pasquariello PS, LaRossa D, et al. (1987) Genera body growth in children with clefts of the lip, palate, and craniofacial structure. Scand J Plast Reconstr Surg Hand Surg 21: 7-14. [Crossref]

Copyright: (C2019 Karia H. This is an open-access article distributed under the terms of the Creative Commons Attribution License, which permits unrestricted use, distribution, and reproduction in any medium, provided the original author and source are credited. 